\title{
One week treatment for Helicobacter pylori infection
}

D Walsh, N Goggin, M Rowland, M Durnin, S Moriarty, B Drumm

\begin{abstract}
Helicobacter pylori is associated with primary antral gastritis, duodenal ulceration, and gastric cancer. Current regimens for treating infection in children using bismuth and antibiotics for two to six weeks are cumbersome. The aim of this study was to evaluate a one week course of treatment. All children undergoing endoscopy were assessed for the presence of $H$ pylori by culture, histology, rapid urease test, and ${ }^{13} \mathrm{C}$ urea breath test. Infected children received a one week course of colloidal bismuth subcitrate 480 $\mathrm{mg} / 1.73 \mathrm{~m}^{2} /$ day (maximum $120 \mathrm{mg}$ four times a day), combined with metronidazole $20 \mathrm{mg} / \mathrm{kg} / \mathrm{day}$ (maximum $200 \mathrm{mg}$ three times a day), and clarithromycin 15 $\mathrm{mg} / \mathrm{kg} /$ day (maximum $250 \mathrm{mg}$ twice a day). To optimise compliance, drugs were dispensed in a 'Redidose' box containing a compartment for each day, and subcompartments marked 'breakfast', 'lunch', 'dinner', and 'bedtime'. Compliance and side effects were assessed immediately after treatment. A urea breath test was performed at least one month after treatment. Twenty two children infected with $H$ pylori were entered into the study; 20 of these took all doses; two children suffered significant side effects (diarrhoea and vomiting). H pylori was eradicated in 21 of the 22 children $(95.45 \% ; 95 \%$ confidence interval $77 \%$ to $100 \%$ ). This study shows that $H$ pylori infection in children can be cleared by a one week course of treatment. (Arch Dis Child 1997;76:352-355)
\end{abstract}

Keywords: treatment; Helicobacter pylori

Department of Paediatrics, University College Dublin; Children's Research Centre, Our Lady's Hospital for Sick Children, Dublin, Ireland

D Walsh

N Goggin

M Rowland

M Durnin

S Moriarty

B Drumm

Correspondence to: Professor B Drumm, Professorial Unit, Children's Research Centre, Our Lady's Hospital for Sick Children,

Crumlin, Dublin 12, Ireland.

Accepted 8 November 1996 Helicobacter pylori is associated with primary cation of $H$ pylori from the gastric mucosa results in healing of gastritis. ${ }^{6-8}$ There is also a strong association between $H$ pylori gastritis and duodenal ulceration in both adults and children. ${ }^{245910}$ Duodenal ulcer disease does not relapse if $H$ pylori is eradicated from the gastric mucosa. ${ }^{711-13}$ Infection with $H$ pylori also appears to be associated with an increased risk of carcinoma of the stomach, especially in those infected as children. ${ }^{14-17}$

Current treatment regimens for $H$ pylori infection in children using bismuth combined with one or two antibiotics for two to six weeks are cumbersome and compliance is difficult. ${ }^{611}$ Studies on adult patients suggest that one week courses of treatment are effective. ${ }^{18-24}$
The aim of this study was to test the efficacy of a one week course of treatment combining colloidal bismuth subcitrate, metronidazole, and clarithromycin in eradicating $H$ pylori in children.

\section{Methods}

Children undergoing upper endoscopy were routinely assessed for the presence of $H$ pylori. Endoscopy was performed under general anaesthetic using Olympus paediatric gastroscopes QIF-P10 or XQ200. Three biopsy specimens were taken from the antral mucosa. One specimen was used for a rapid urease test (Clo, Delta West, Australia). A second specimen was fixed in $10 \%$ neutral formalin, embedded in paraffin wax, and cut at five micron thickness. The sections were then stained with haematoxylin and eosin for light microscopy. Further staining with cresyl violet allowed for easy identification of the spiral shaped organisms on the surface of the gastric mucosa. The third specimen was placed in RPMI 1640 (Gibco) tissue culture medium containing fetal calf serum. Culture was performed by inoculation of minced biopsy specimens onto Columbia blood agar (Gibco) plates containing $7 \%$ (vol $/ \mathrm{vol}$ ) defibrinated horse blood, and held for five to seven days at $37^{\circ} \mathrm{C}$, in an atmosphere of $5 \%$ oxygen and $10 \%$ carbon dioxide $\left(\mathrm{CO}_{2}\right)$. Organisms were identified as $H$ pylori if they were Gram negative, had a characteristic spiral shape on phase contrast microscopy, and showed urease, oxidase, and catalase activity. ${ }^{25}$

Children were considered to be infected if $H$ pylori was cultured from gastric biopsy specimens. If culture was negative, they were considered infected only if both the rapid urease test was positive and characteristic spiral shaped organisms were seen on histology.

$\mathrm{A}^{13} \mathrm{C}$ urea breath test was performed on each infected child before treatment. A repeat test was carried out one and two months after the completion of treatment. After a two hour fast, a baseline breath sample was taken. Children were then given an oral dose of ${ }^{13} \mathrm{C}$ labelled urea: $50 \mathrm{mg}$ if the child was less than $50 \mathrm{~kg}$ body weight, or $75 \mathrm{mg}$ if over $50 \mathrm{~kg}$ (99 atom\%, Cambridge Isotopes, Cambridge, MA, USA). The labelled urea was given in a glucose polymer solution (50 mg Polycose in $7.5 \mathrm{ml}$ water). Breath samples were repeated at 15 and 30 minutes after ingestion. ${ }^{13} \mathrm{C}$ enrichment was determined by isotope ratio mass spectrometry. Isotope enrichment was expressed as corrected delta $(\delta)$ per thousand $(0 / 00)$ relative to the international standard Pee Dee belemnite 
Table 1 Schedule of seven day course of treatment for $\mathrm{H}$ pylori infection in children

\begin{tabular}{llll}
\hline Treatment & Total daily dose & Times per day & Maximum dosage \\
\hline Colloidal bismuth subcitrate & $480 \mathrm{mg} / 1.73 \mathrm{~m}^{2}$ body surface area & Four & $120 \mathrm{mg}$ four times daily \\
Clarithromycin & $15 \mathrm{mg} / \mathrm{kg}$ & Two & $250 \mathrm{mg}$ twice daily \\
Metronidazole & $20 \mathrm{mg} / \mathrm{kg}$ & Three & $200 \mathrm{mg}$ three times daily \\
\hline
\end{tabular}

limestone. $\delta 0 / 00=\left\{{ }^{\mathrm{R}}\right.$ sample $\left./{ }^{\mathrm{R}} \mathrm{PDB}-1\right\} \times 10$, where $\mathrm{R}$ is the isotope ratio $\left({ }^{13} \mathrm{C}:{ }^{12} \mathrm{C}\right)$ of the sample or standard. A positive result was defined as a $\delta^{13} \mathrm{CO}_{2}$ excretion of $>3.5 / \mathrm{ml}^{26}$

\section{TREATMENT}

Infected children were started on a seven day course of treatment as outlined in table 1. Possible side effects were discussed with parents and informed consent was obtained. The parents of two children refused to consent to treatment. Parents received an instruction sheet detailing how and when to take the drugs. The importance of compliance was stressed. The tablets were dispensed in a 'Redidose' box, containing a compartment for each day, and subcompartments marked 'breakfast', 'lunch', 'dinner', and 'bedtime'. They were asked to return the box along with any unused tablets at their first review. Children who were unable to take tablets received the medication in liquid form $(n=4)$ and parents were asked to make a note of any doses missed. Patients were reviewed one day after the end of treatment. Returned medication was documented. Parents and children were asked about specific side effects, including taste disturbance, nausea, vomiting, diarrhoea, black stools, abdominal pain, or any other symptoms noted while taking the drugs.

All children were further reviewed at least four weeks after the end of treatment, and a urea breath test was done. This process was repeated at least eight weeks after the completion of treatment.

\section{Results}

During the 13 month study period, October 1994 to October 1995, 187 upper endoscopies were performed on 168 children. Indications for endoscopy were as outlined in table 2 . Twenty eight $(16.7 \%)$ were diagnosed as having $H$ pylori infection. Twenty two children were entered into the study. Children were excluded if the parents did not wish to have their child participate in the study $(n=2)$, or if the child was suffering from a severe underlying medical condition, where $H$ pylori infection was an incidental finding $(\mathrm{n}=4)$.

The mean age of infected children was 12.1 years (range 14 months to 16 years). Twenty had a urea breath test before treatment. In the

Table 2 Indications for endoscopy; values are number (\%)

\begin{tabular}{lll}
\hline Symptoms & All children & Treatment group \\
\hline Failure to thrive +/- diarrhoea & $58(31)$ & $4(18)$ \\
Abdominal pain & $51(27)$ & $11(50)$ \\
Oesophageal symptoms & $20(11)$ & $4(18)$ \\
Haematemesis & $13(7)$ & $0(0)$ \\
Inflammatory bowel disease & $24(13)$ & $2(9)$ \\
Liver disease/varices & $11(6)$ & $0(0)$ \\
Other & $10(5)$ & $1(5)$ \\
Total & 187 & 22 \\
\hline
\end{tabular}

other two children, there was insufficient $\mathrm{CO}_{2}$ in the pretreatment breath test samples. Culture of a gastric biopsy was carried out in 20 of the children, and was positive in all cases. In two children, culture was not performed, but both the rapid urease test and histology confirmed infection.

Endoscopy findings included nodularity of the antral mucosa, which was present in 14 children, duodenitis in three, duodenal ulceration in one, oesophagitis in two, hiatus hernia in one, and a normal examination in eight children. Some children had more than one finding.

Twenty children took all doses of the regimen. One child omitted to take one tablet. A 17 month old child spat out or vomited many of the doses (elixir). All 22 children had a urea breath test performed at least one month after completion of treatment. $H$ pylori was eradicated in 21 of 22 children treated. The eradication rate was therefore $95.45 \%$ (95\% confidence interval $77 \%$ to $100 \%$ ). Eighteen children have had a further urea breath test performed at least two months after completion of treatment. All children who were negative at one month remained negative on repeat testing. The one child who failed to clear the infection still had a positive urea breath test two months after treatment.

Fifteen children noted no side effects apart from black stools, which was expected due to the inclusion of a bismuth containing compound in the regimen. Two children $(9 \%)$ had significant side effects. One of these children complained of multiple symptoms, including a burning sensation of the tongue, vomiting for one day, persistent diarrhoea, and nightmares. A second child vomited or spat out approximately 10 doses of elixir, and was noted to be irritable during the period of treatment. Milder side effects were observed by five children. Four $(18 \%)$ complained of a bad taste or burning sensation on the tongue. The fifth child was nauseated for two days. None of the children withdrew from the study because of side effects.

\section{Discussion}

This study shows that a one week course of treatment can eradicate $H$ pylori infection in children. Current regimens generally require two to six weeks of treatment and many people therefore fail to complete the full course. Compliance is even more difficult in young children, who may refuse to take the medicine. A recent study from Brazil has suggested that a one week course of treatment might be effective in eradicating $\mathrm{H}$ pylori. ${ }^{27}$ We decided to formally assess the efficacy of a one week course of treatment while trying to ensure maximum compliance. The success rate for eradication of $H$ pylori in this study was $95.45 \%$. However, compliance 
was very closely monitored in this group. It is unlikely that this level of compliance would be achieved in routine practice. The one week course should, however, ensure much better compliance than previous treatment regimens. The 'Redidose' box used in 18 of the children in this study represents an attempt to improve compliance by presenting a visual reminder of what medications to take and when. Feedback from parents suggested that it was very effective in its purpose.

Studies in relation to treatment of $H$ pylori have been hampered by the need to perform repeat endoscopies. The ${ }^{13} \mathrm{C}$ urea breath test provides an ideal, non-invasive method for evaluating treatment. We have recently shown that the urea breath test is highly sensitive and specific in diagnosing $H$ pylori infection in children. Furthermore, it is very accurate in determining the success of treatment when compared with endoscopy. ${ }^{26}$

The development of antibiotic resistance by $H$ pylori is a concern. Metronidazole is very effective in eradicating $H$ pylori in vivo. However, resistance to metronidazole often develops in those who have previously been treated with this antibiotic. ${ }^{28}$ Clarithromycin is a new macrolide antibiotic (6-methoxyerythromycin). It has a similar antimicrobial spectrum to erythromycin. It is, however, more acid stable and has higher bioavailability and fewer alimentary side effects. Its metabolite, 14-OH-clarithromycin, is more active than the parent compound in vitro against several pathogens. A longer half life allows for twice daily dosing. ${ }^{29}$ Preliminary studies suggest that H pylori strains may develop resistance to clarithromycin. Subsequent studies should therefore focus on other antibiotic agents such as amoxycillin, where resistance appears to be very rare.

The question as to whether children infected with $H$ pylori should be treated or not is still controversial. $H$ pylori is very prevalent in developing countries, where up to $80 \%$ are infected by 20 years of age. ${ }^{30}$ In children with chronic $H$ pylori associated gastritis, there is no evidence of an association between $H$ pylori infection and abdominal pain. In an earlier study, we, and our colleagues in Toronto, evaluated symptoms in children undergoing upper endoscopy before checking their $H$ pylori status. $^{31}$ It was not possible to distinguish between infected and non-infected children on the basis of symptoms. In a subsequent study, we evaluated children's symptoms following treatment of $H$ pylori infection. ${ }^{32}$ Following eradication of $H$ pylori, there was resolution of symptoms in those children who had $H$ pylori gastritis associated with duodenal ulcer disease. However, there was no change in symptoms in children with $H$ pylori gastritis alone. The presence or absence of symptoms failed to differentiate between those who had cleared the infection, and those who remained infected. In contrast, duodenal ulcer disease is an indication for the treatment of $H$ pylori infection in adults and children. Almost $100 \%$ of children with duodenal ulcer disease will have $H$ pylori associated gastritis. ${ }^{2}{ }^{10}$ If $\mathrm{H}$ pylori is eradicated from the gastric mucosa, duodenal ulcer disease will not relapse. ${ }^{711-13}$

More recently, epidemiological studies suggest an association between $H$ pylori infection and the subsequent development of gastric cancer. ${ }^{14-17}$ This has resulted in $H$ pylori being considered a group 1 carcinogen. ${ }^{33}$ If these studies are confirmed it may soon be necessary to consider treating all children with $H$ pylori infection of the gastric mucosa. Short courses of therapy, which ensure maximum compliance, will be required if large numbers of children are to be treated.

We thank Dr Julian Thomas, Department of Child Health, University of Newcastle, and Philip Johnson, Bureau of Stable Isotope Analysis (BSIA), Brentford, Middlesex, for performing stable isotope analysis. This project was supported in part by BIOMED Concerted Action CT93-1239.

1 Drumm B, Sherman P, Cutz E, Karmali M. Association of Campylobacter pylori on the gastric mucosa with antral gastritis in children. N Engl F Med 1987;316:1557-61.

2 Drumm B. Helicobacter pylori. Arch Dis Child 1990;6: 1278-82.

3 Drumm B. Helicobacter pylori in the pediatric patient. Gastroenterol Clin N Am 1993;22:169-82.

4 Blaser MJ. Epidemiology and pathophysiology of Campylobacter pylori infections. Rev Infect Dis 1990;12:99-106.

5 Peterson WL. Helicobacter pylori and peptic ulcer disease. N Engl f Med 1991;324:1043-8.

6 Drumm B, Sherman P, Chiasson D, Karmali M, Cutz E. Treatment of Campylobacter pylori-associated antral gastritis in children with bismuth subsalicylate and gastritis in children with bismuth

7 Coughlan JG, Gilligan D, Humphries H, et al. CampyloCoughlan JG, Gilligan D, Humphries $\mathrm{H}$, et al. Campylo-
bacter pylori and recurrence of duodenal ulcers-a 12 bacter pylori and recurrence of duodenal ulcers
month follow-up study. Lancet 1987;ii:1109-11.

8 Humphreys H, Bourke S, Dooley C, et al. Effect of treatment of Campylobacter pylori in peptic disease: a randomised prospective trial. Gut 1988;29:279-83.

9 Hassal E, Dimmick JE. Unique features of Helicobacter pylori disease in children. Dig Dis Sci 1991;36:417-23.

10 Kilbridge PM, Dahms BB, Czinn SJ. Campylobacter pyloriassociated gastritis and peptic ulcer disease in children. $\mathrm{Am}$ $\mathfrak{f}$ Dis Child 1988;142:1149-52.

11 Israel D, Hassall E. Treatment and long term follow-up of Helicobacter pylori-associated disease in children. $\mathcal{F}$ Pediatr 1993;123:53-8.

12 Yeung CK, Fu KH, Yuen KY, et al. Helicobacter pylori and associated duodenal ulcer. Arch Dis Child 1990;65:1212-6.

13 Marshall BJ, Goodwin CS, Warren JR, et al. Prospective double-blind trial of duodenal ulcer relapse after eradication of Campylobacter pylori. Lancet 1988;ii:1437-42.

tion of Campylobacter pylori. Lancet 1988;ii:1437-42.
14 Forman D, Newell DG, Fullerton F, et al. Association between infection with Helicobacter pylori and risk of gasbetween infection with Helicobacter pylori and risk of gas-
tric cancer: evidence from a prospective investigation. BMF tric cancer: eviden

15 Nomura A, Stemmerman GN, Chyou PH, et al. Helicobacter pylori infection and gastric carcinoma among Japanese Americans in Hawaii. N Engl f Med 1991;325:1132-6.

16 Parsonnet J, Friedman GD, Vandersteen DP, et al. Helicobacter pylori infection and the risk of gastric carcinoma. N Engl f Med 1991;325:1127-31.

17 Blaser MJ, Chyou PH, Nomura A. Age at establishment of Helicobacter pylori infection and gastric carcinoma, gastric ulcer, and duodenal ulcer risk. Cancer Res 1995;55:562-5.

18 Hosking SW, Ling TK, Chung SC, et al. Duodenal ulcer healing by eradication of Helicobacter pylori without antiacid treatment: randomised controlled trial. Lancet 1994;
343:508-10.

19 Bazzoli F, Zagari RM, Fossi S, et al. Short-term low-dose triple therapy for the eradication of Helicobacter pylori. triple therapy for the eradication of Helico
Eur 7 Gastroenterol Hepatol 1994;6:773-7.

20 Chen T, Tsay SH, Chang FY, Lee SD. Triple therapy for the eradication of Helicobacter pylori and reduction of duodenal ulcer relapse: comparison of 1 week and 2 week regimens and recrudescence rates over 12 months. $\mathcal{F}$
Gastroenterol Hepatol 1995;10:300-5.

21 de Boer W, Driessen W, Jansz A, Tytgat G. Effect of acid suppression on efficacy of treatment for Helicobacter pylori infection. Lancet 1995;345:817-20.

22 Ozmen MM, Johnson CD. Is short-term triple therapy with lansoprazole, clarithromycin, and metronidazole a definitive answer for Helicobacter pylori infection?[letter] $A m \mathcal{F}$ Gastroenterol 1995;90:1542.

23 Matysiak-Budnik T, Briet F, Heyman M, Megraud F. Laboratory-acquired Helicobacter pylori infection [letter]. Lancet 1995;346:1489-90.

24 Bell GD Powell KU, Burridge SM, et al. Rapid eradication of Helicobacter pylori infection. Aliment Pharmacol Ther 1995;9:41-6.

25 Clyne M, Drumm B. Adherence of Helicobacter pylori to primary human gastrointestinal cells. Infect Immun 1993; 61:4051-7. 
26 Rowland M, Lambert I, Gormally S, et al. ${ }^{13} \mathrm{C}$ urea breath test for the diagnosis of Helicobacter pylori in children [abst]. Proc Br Paediatr Assoc Annual Meeting 1996;68:46.

27 Querioz DM, Moura SB, Mendes EN, Rocha GA, Barbosa AJ, de Carvalho AS. Effect of Helicobacter pylori eradication on G-cell and D-cell density in children. Lancet 1994; 343:1191-3.

28 Banatvala N, Davies GR, Abdi Y, et al. High prevalence of Helicobacter pylori metronidazole resistance in migrants to east London: relation with previous nitroimidazole exposure and gastroduodenal disease. Gut 1994;35:1562-6. $29 \begin{gathered}\text { Bergeron MG. Microbial spectrum and pharmacokinetic } \\ \text { profile of clarithromycin. Infections in Medicine 1993; }\end{gathered}$ $\operatorname{Dec}(S): 12-20$
30 Graham DY, Adam E, Reddy GT, et al. Seroepidemiology of Helicobacter pylori infection in India. Dig Dis Sci 1991;36: 1084-8

31 Reifen R, Rasooly I, Drumm B, Murphy K, Sherman P. Helicobacter pylori infection in children. Is there specific symptomatology? Dig Dis Sci 1994;39:1488-92.

32 Gormally SM, Prakash N, Durnin M, et al. Association of symptoms with Helicobacter pylori infection in children. $\mathcal{f}$ Pediatr 1994;126:753-6.

33 IARC. Monographs on the evaluation of carcinogenic risks to humans. Vol 61. Schistosomes, liver flukes and Helicobacter pylori. Lyon: International Association for Research on Cancer, 1994. 